\title{
Chemical Kinetics and Self-Ignition in a Model Supersonic Hydrogen-Air Combustor
}

\author{
C. J. Sung* \\ Princeton University, Princeton, New Jersey 08544 \\ J. G. $\mathrm{Li}^{\dagger}$ and $\mathrm{G} . \mathrm{Yu}^{\dagger}$ \\ Chinese Academy of Sciences, 10080 Beijing, People's Republic of China \\ and \\ C. K. Law ${ }^{\ddagger}$ \\ Princeton University, Princeton, New Jersey 08544
}

\begin{abstract}
Self-ignition tests of a model scramjet combustor were conducted by using parallel sonic injection of gaseous hydrogen from the base of a blade-like strut into a supersonic vitiated airstream. The range of stagnation pressure and temperature studied varied from 1.0 to 4.5 MPa and from 1300 to $2200 \mathrm{~K}$, respectively. Experimental results show that the self-ignition limit, in terms of either global or local quantities of pressure and temperature, exhibits a nonmonotonic behavior resembling the classical homogeneous explosion limit of the hydrogen-oxygen system. Specifically, for a given temperature, increasing pressure from a low value can render a nonignitable mixture to first become ignitable, then nonignitable again. This correspondence shows that, despite the globally supersonic nonpremixed configuration studied herein, ignition is strongly influenced by the intricate chemical reaction mechanism and thereby exhibits the homogeneous explosion character. Consequently, self-ignition criteria based on a global reaction rate approximating the complex chemistry are inadequate. An auxiliary computational study on counterflow ignition was also conducted to systematically investigate the contamination effects of vitiated air. Results indicate that the net contamination effects for the present experimental data are expected to be substantially smaller than contributions from the individual contamination species because of the counterbalancing influences of the $\mathrm{H}_{2} \mathrm{O}$-inhibition and NO-promotion reactions in effecting ignition.
\end{abstract}

\section{Introduction}

$\mathbf{C}$ ONSIDERABLE fundamental research has been conducted in response to the interest in the development of scramjet engines and scram accelerators. ${ }^{1-3}$ Because hydrogen-air is the preferredreactant system for scramjet engines and because of the significantly reduced residence time available for reaction to proceed subsequent to mixing, a comprehensiveunderstanding of the supersonicignition phenomena must necessarily include a reasonably realistic description of the associated chemistry and a corresponding exposition of its implications. Recognizing the need to account for finite-ratekinetics, Huber et al. ${ }^{4}$ developed a criterion for self-ignition by assuming that the ignition time is equal to the mixture residence time and by using a global reaction rate expression to describe the finite-rate chemistry.

The use of a global reaction expression in combustion modeling has enjoyed a long history of acceptance and, indeed, is still the description of preference in many present computational modelings of complex flows. However, because the global reaction expression compresses the response of a chemical system, which is fundamentally described by a multitude of elementary reactions involving a myriad of reaction intermediates, and because each of these elementary reactions has its own characteristic dependence on the local environment of temperature, pressure, and concentration, the system response described by such an empirical, global expression must be rather limited in the thermodynamic range of applicability. By implication, then, the associated empirically determined global kinetic constants of activationenergy, reaction orders, and frequency

Presented as Paper 98-0722 at the AIAA 36th Aerospace Sciences Meeting, Reno, NV, Jan. 12-15, 1998; received Feb. 23, 1998; revision received Sept. 9, 1998; accepted for publication Oct. 4, 1998. Copyright (C) 1998 by the authors. Published by the American Institute of Aeronautics and Astronautics, Inc., with permission.

${ }^{*}$ Research Staff, Department of Mechanical and Aerospace Engineering. Senior Member AIAA.

${ }^{\dagger}$ Professor, Institute of Mechanics. Member AIAA.

${ }^{\ddagger}$ Robert H. Goddard Professor, Department of Mechanical and Aerospace Engineering. Fellow AIAA. factor must also have only a limited range of applicability. Furthermore, because elementary reactions can either facilitate or retard the progress of an overall reaction mechanism depending on the local thermodynamic environment, it is then reasonable to anticipate that the use of a given set of global kinetic constants could totally miss possible trend reversals as the kinetic expression is applied beyond the range over which it is determined.

A most dramatic example of such kinetic intricacies is the wellknown explosion limits of the hydrogen-oxygen system, which is also our system of interest. Figure 1 shows the limit boundary in terms of the temperature and pressure of an enclosed homogeneous mixture. The characteristics of the limit can be considered for either a fixed temperature or a fixed pressure. Thus, it is seen that, over a certain temperature range, as the system pressure is continuously increased, the system changes from no explosion, to explosion, to no explosion, to explosion again, thereby demonstrating the nonlinear effect of the system pressure on the mixture ignitability. In particular, the middle, second explosion limit segment demonstrates that ignition is inhibited with increasing system pressure, a response that intrinsically cannot be described by a global reaction mechanism with an overall reaction order that is usually taken to be constant. Furthermore, if we consider the system response for a given pressure, then Fig. 1 shows that the system ignitability changes drastically as the temperature crosses the limit line. Thus, we expect that the effective activation energy controlling the system response would also change from a large value to a smaller value as the system temperature increases beyond the limit line.

Recognizing the importance of such nonlinear intricacies with the hydrogen-oxygen system, Nishioka and $\mathrm{Law}^{5}$ computationally simulated the ignition of a hydrogen-air laminar mixing layer with detailed chemistry and transport descriptions. The results convincingly demonstrate that the state of the second explosion limit is an important boundary in the ignition response. This limit is controlled by the competition between the $\mathrm{H}-\mathrm{O}_{2}$ reactions

$$
\begin{gathered}
\mathrm{H}+\mathrm{O}_{2} \rightarrow \mathrm{OH}+\mathrm{O} \\
\mathrm{H}+\mathrm{O}_{2}+\mathrm{M} \rightarrow \mathrm{HO}_{2}+\mathrm{M}
\end{gathered}
$$




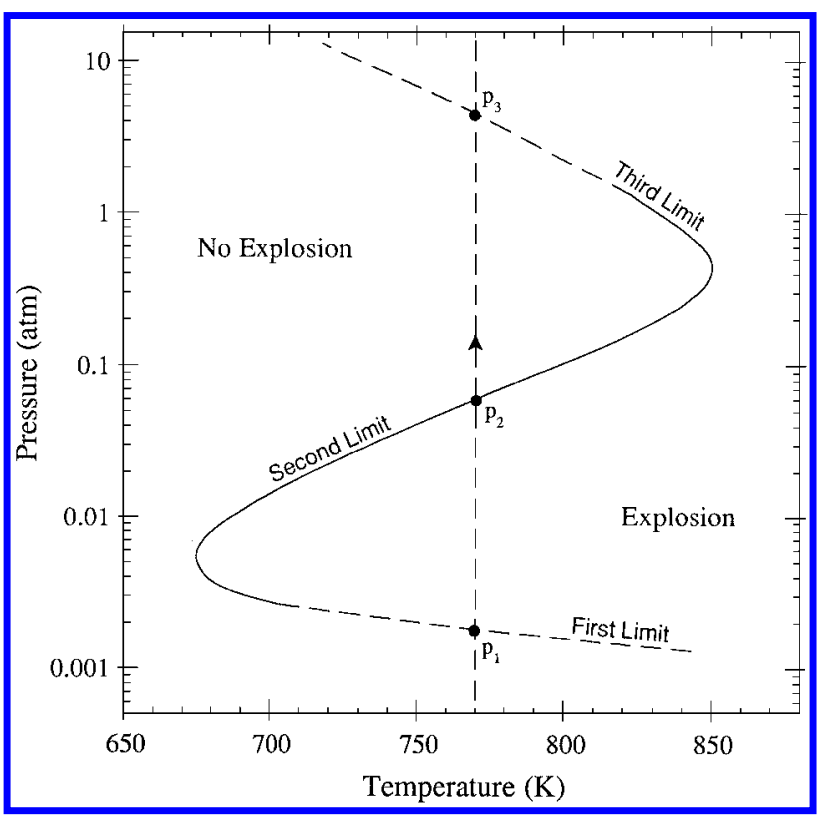

Fig. 1 Demonstration of the explosion limits of homogeneous hydrogen-oxygen system, showing the limit boundary in terms of the temperature and pressure.

in which reaction (1) is a two-body,temperature-sensitivebranching reaction with an activation energy of $16.44 \mathrm{kcal} / \mathrm{mole}$, whereas reaction (2) is a three-body,temperature-insensitiveterminating reaction because the intermediate $\mathrm{HO}_{2}$ is relatively inactive. Thus, increasing temperature facilitates reaction (1) and, hence, the overall ignitability, whereas increasing pressure facilitates the three-body reaction (2) over the two-body reaction (1) and, hence, retards the overall ignitability. This, therefore, explains the positive slope of the second explosion limit in Fig. 1, with the limit representing the transition in dominance between these two reactions, which is quantitatively defined through the crossovertemperature $T_{c}(p)$, which is a function of pressure. ${ }^{6}$

The simulated results of Nishioka and $\mathrm{Law}^{5}$ then show that increasing pressure indeed prolongs the ignition delay when the system pressure traverses that of the crossover. Furthermore, when the maximum temperature in the flow, $T_{m}$, is larger than $T_{c}$, the system response is controlled by reaction (1) and the ignition distance varies approximately Arrheniusly with an effective activation energy that is close to that for reaction (1). For $T_{m}$ less the $T_{c}$, ignition is retarded. However, the continuous accumulation of the $\mathrm{HO}_{2}$ radical eventually facilitates the reaction

$$
\mathrm{HO}_{2}+\mathrm{HO}_{2} \rightarrow \mathrm{H}_{2} \mathrm{O}_{2}+\mathrm{O}_{2}
$$

followed by the branching reaction

$$
\mathrm{H}_{2} \mathrm{O}_{2}+\mathrm{M} \rightarrow 2 \mathrm{OH}+\mathrm{M}
$$

which has a relatively high activation energy of $45.5 \mathrm{kcal} / \mathrm{mole}$ but will eventually still lead to system runaway given a sufficiently long time. The ignition distance was again found to vary approximately Arrheniusly, but now with an effective activationenergy that is close to that of reaction (4)

Whereas the study of Nishioka and $\mathrm{Law}^{5}$ involves laminar mixing layers and, hence, is highly idealized, nevertheless it is reasonableto expect that influences of the crossovertemperature $T_{c}$ and the system pressure $p$ are so dominating that they should be appropriately manifested in real systems. Thus, the primary objective of the present study is to conductexperimentalself-ignitiontests of a model scramjet combustor and to explore/demonstrate the importance of these intrinsic chemical kinetic effects. Because typical static pressures at the entrance of supersonic combustors range from approximately 0.1 to $1.5 \mathrm{~atm}$ depending on the operating parameters for the flight mission, such as the Mach number and the altitude, ${ }^{1,3}$ the study will emphasize the system response pertinent to such practically realistic ranges. We shall also reexamine the ignition criterion of Huber et al., ${ }^{4}$ which, being dependent on a global reaction rate, obviously cannot describe the nonmonotonic pressure effect mentioned earlier. On the other hand, the associated global activation energy used in Ref. 4 is around $19 \mathrm{kcal} / \mathrm{mole}$, which is close to that of the branching reaction (1). It is, therefore, of interest to assess the validity of the Ref. 4 criterion within the pressure range of practical supersonic combustors. Indeed, based on our experimental self-ignition data with variations of airstream temperature and system pressure, we shall show in due course that the Ref. 4 ignition criterion is qualitatively inadequate to be comprehensive in the pressure range of interest.

The second, major objective of the present study is to assess the effects of using vitiated air in the experiments. This is an important consideration in laboratory studies of supersonic combustion because the use of vitiated air to simulate the flight enthalpy implies that the test media are inevitably contaminated by species that are not present in the actual atmosphere. Particularly, because the vitiated air in the present experimentation was produced by burning hydrogen in oxygen-enriched air, the resulting high-enthalpy airflow contains a substantial amount of $\mathrm{H}_{2} \mathrm{O}$ and $\mathrm{NO}$. It is well known ${ }^{6}$ that small amounts of $\mathrm{H}_{2} \mathrm{O}$ and $\mathrm{NO}$, respectively, inhibit and promote ignition, and the net effect of simultaneous $\mathrm{H}_{2} \mathrm{O}$ and NO contaminations on the ignition response is, therefore, unclear a priori. We shall, therefore, conduct a systematic computational study with detailed chemistry and transport, using the prototypical counterflow configuration, to identify the effects of contamination on ignition. The computed results would also provide insight into the interpretation of the present experimental data, especially their implication for practical supersonic operations.

In the following we shall sequentiallypresent the supersonic combustion facility, experimental considerations, experimental results and the associated discussion, and computational investigation of the effects of contamination.

\section{Experimental Considerations}

\section{Supersonic Combustion Facility}

Because details of the test facility, shown in Fig. 2, have been described in Ref. 7, only the important characteristicsare highlighted. In the experimentation, high-temperature vitiated test air was produced by burning hydrogen, oxygen, and air in a heater, with the resulting oxygen volume fraction equal to that of normal air. The heater can provide vitiated air up to its maximum capability with a temperature of $2200 \mathrm{~K}$, a pressure of $4.5 \mathrm{MPa}$, and a flow rate of $1.5 \mathrm{~kg} / \mathrm{s}$.

An integrated modular structure was designed for the study of the combustion of a hydrogen jet injected parallel into a supersonic airstream to avoid unnecessary shock waves introduced by a strut. Especially, the upper and lower contour walls of the strut and the combustor wall form two half-parts of a nozzle that produces a twodimensional supersonic airflow of Mach number 2.5. This combustor entrance condition basically simulates the free flight of Mach number 7 and 25-km altitude. The overall blade-like strut is $8.4 \mathrm{~mm}$ in width and $30 \mathrm{~mm}$ in length and has a narrow slot of $0.95 \times 20$ $\mathrm{mm}$ in the center for the hydrogen injection. In addition, the leading part of the strut is water cooled to avoid burnout.

The supersonic combustion chamber is a rectangular duct with an entrance cross section of $30 \times 30 \mathrm{~mm}$. The duct is composed of three sections. The side walls are parallel to the two-dimensional nozzle with boundary-layercorrection angles of $0.5,1.5$, and $3 \mathrm{deg}$, respectively. To monitor the static pressure distribution within the combustor, 10 pressure ports along the center line of each side wall are arranged.

The gas flow system is computer controlled to achieve the required accuracy and reliability. The computer also serves as the data acquisition and processing unit.

\section{Experimental Procedures}

A typical experiment running duration is $7 \mathrm{~s}$. The major gases (air, $\mathrm{O}_{2}$, and $\mathrm{H}_{2}$ ) are released $1 \mathrm{~s}$ after the pilot air and hydrogen are ignited by a spark. It takes $0.8 \mathrm{~s}$ to achieve the required temperature and pressure in the heater, as shown by the time variations of 


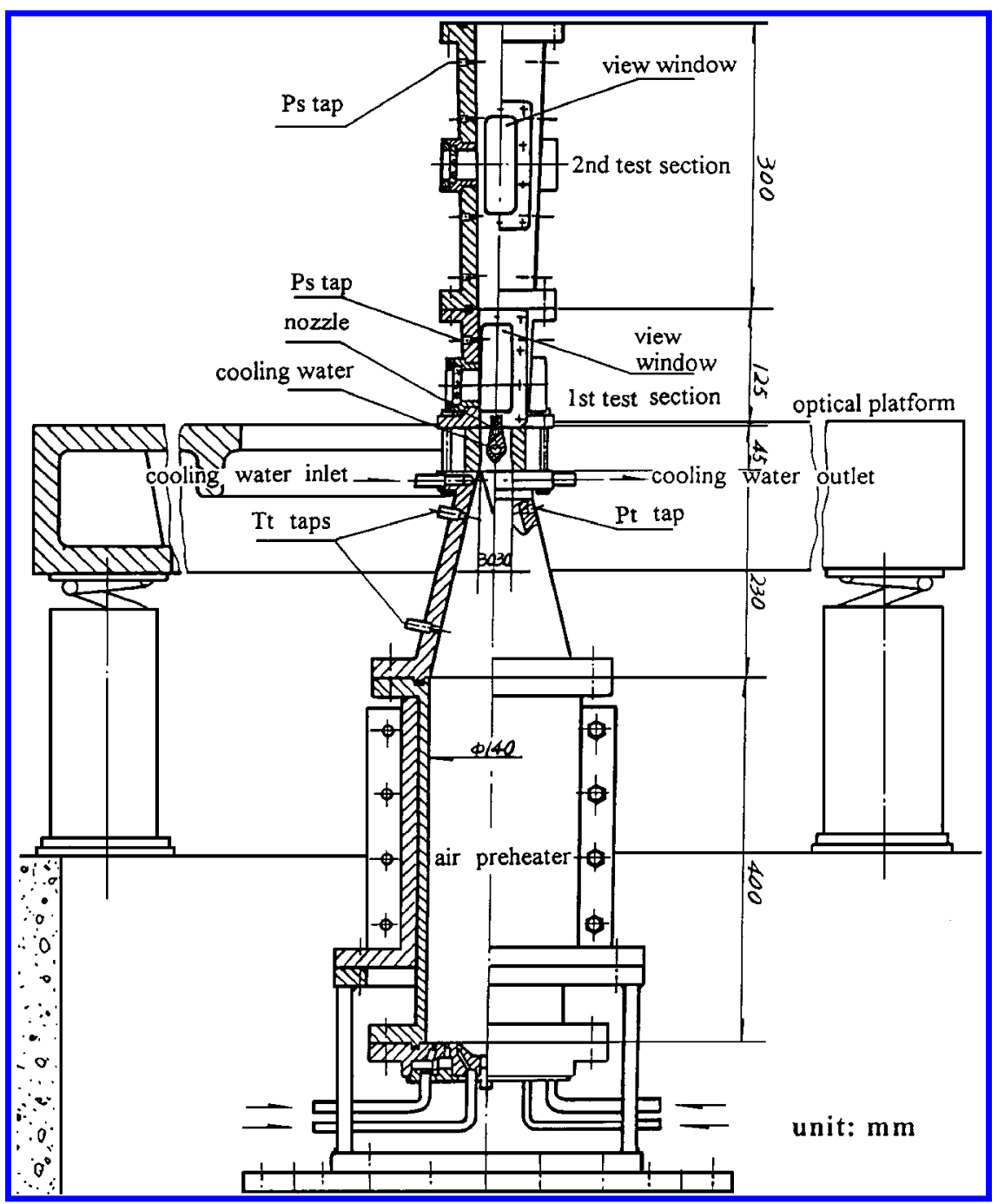

Fig. 2 Schematic of the supersonic combustion facility.

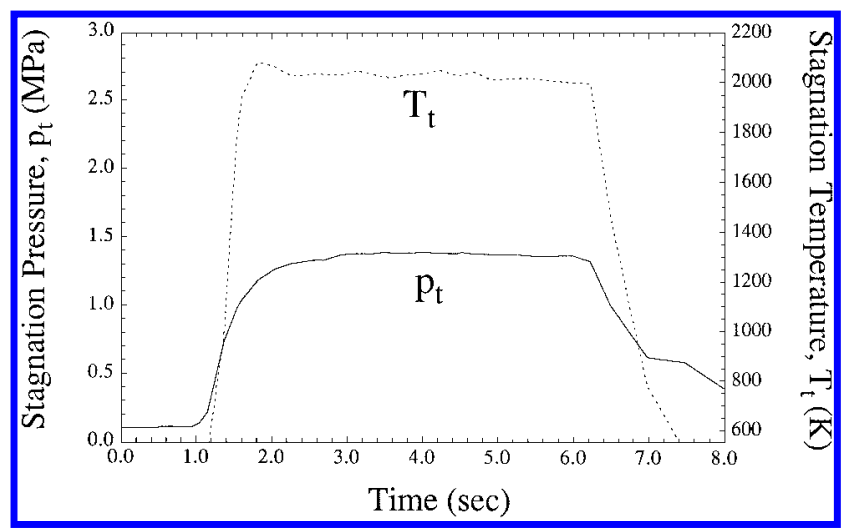

Fig. 3 Typical time variations of the stagnation pressure $p_{t}$ and stagnation temperature $T_{t}$.

pressure and temperature in Fig. 3. Figure 4 plots the static pressure distribution within the test section as a function of time. It is seen in Figs. 3 and 4 that the supersonic flowfield reaches steady state within $2 \mathrm{~s}$. Once the Mach 2.5 supersonic air flow is established, hydrogen is injected at sonic speed into the combustor. If ignition is achieved and combustion subsequently sustained, the static pressure in the combustor is increased immediately, as demonstrated in Fig. 4. In addition, Fig. 4 shows that the pressure distribution is stable after the flame is stabilized.

A series of experiments was conducted with the stagnation temperature $T_{t}$ ranging from 1300 to $2200 \mathrm{~K}$ and the stagnation pressure $p_{t}$ ranging from 1 to $4.5 \mathrm{MPa}$. The overall equivalence ratio is kept

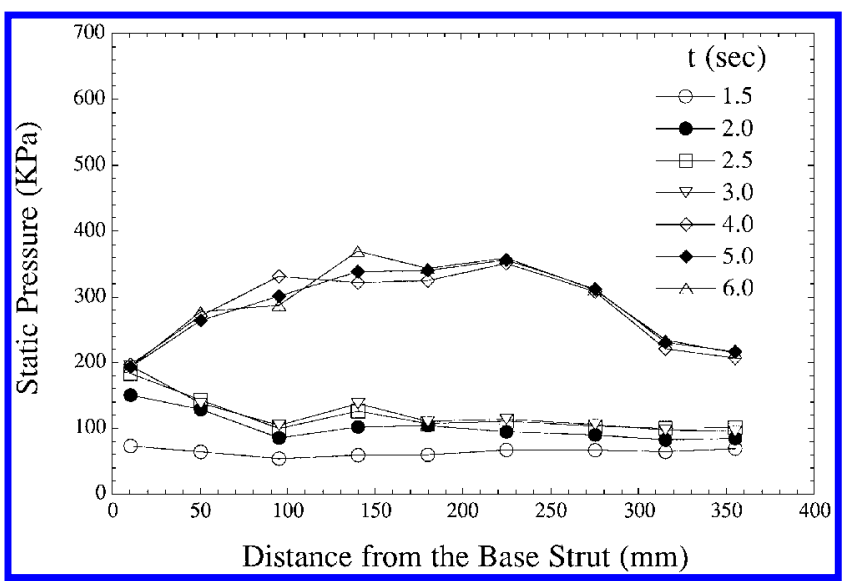

Fig. 4 Typical distributions of the static pressure within the test section at different times, for $p_{t}=28.1 \mathrm{~atm}$ and $T_{t}=1785 \mathrm{~K}$.

constant at 0.6 such that the flow rates of hydrogen and vitiated air vary from run to run. Taking $T_{t}=1700 \mathrm{~K}$ as an example, the flowrate ranges of hydrogen and vitiated air are 4-18 and 220-990 g/s. For a given stagnation pressure, the stagnation temperature is gradually raised until self-ignition is attained.

Determination of the state of self-ignition is accomplished by visualization and pressure distribution. A Panasonic M9000 video camera of 25 frames/s is used to monitor the ignition process. For the nonignitable situations, the interior of the combustor appears to be dark, and there is no sudden increase in combustor pressure. When self-ignitionand stable flame are achieved, a bright flame is observed 
through the view windows, and a diamond shaped flame also appears at the exit of the combustor, accompanied by a substantial increase in pressure.

\section{Experimental Results on Self-Ignition \\ Self-Ignition Limits: Global Response}

Figure 5 summarizes the response of self-ignition in terms of the global system parameters as $T_{t}$ and $p_{t}$. Open and closed symbols denote nonignitableand ignitable conditions, respectively. The solid line represents the self-ignition limit, separating ignitable and nonignitable states. It is seen from Fig. 5 that, for a fixed $p_{t}$, the system ignites with increasing stagnation temperature. More importantly, however, the self-ignition limit within the pressure range of investigation exhibits a nonmonotonic behavior, which resembles the first and second homogeneous explosion limits of hydrogen-oxygen mixtures shown in Fig. 1. Specifically, for a given $T_{t}$ with increasing $p_{t}$, the system changes from nonignitable to ignitable and then nonignitable again. Such a nonmonotonic response, therefore, supports our suggestion of the importance of chain branching-termination competition in effecting ignition under supersonic conditions. Furthermore, it also indicates that the Huber et al. ${ }^{4}$ criterion, which predicts a monotonic promotion in achieving ignition by increasing either pressure or temperature, is only adequate in the range of lower pressures.

Experimentally we also observed two different modes of selfignition. For the first mode, ignition occurs rather spontaneously, whereas for the second mode, ignition is initiated far downstream and then propagates upstream, with a typical delay time of $0.2 \mathrm{~s}$. Figure 6, therefore, differentiatesthe self-ignition data of Fig. 5 into these two ignition modes. It is seen that the nonmonotonic behavior is preserved for both modes and that the downstream-initiated ignition mode is the precursor of spontaneous ignition. It may be

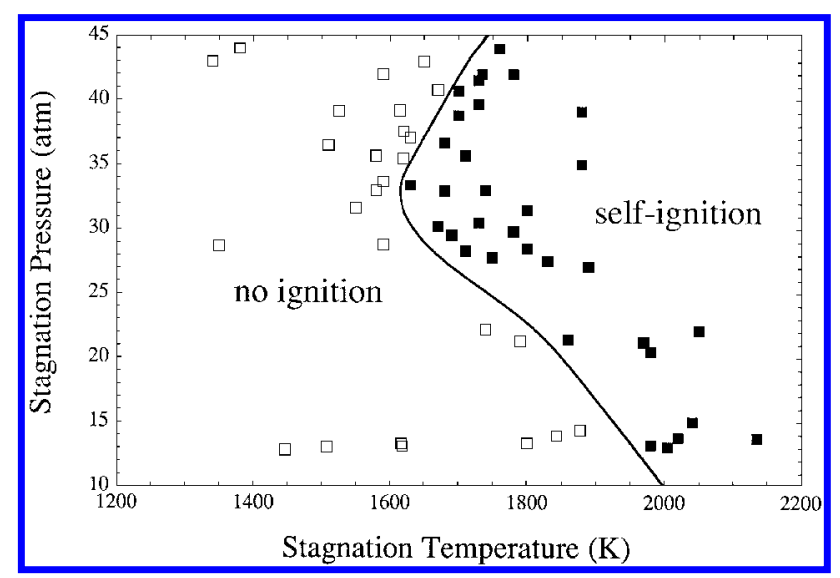

Fig. 5 Limit boundary of self-ignition in terms of the stagnation pressure and stagnation temperature; symbols are the experimental data.

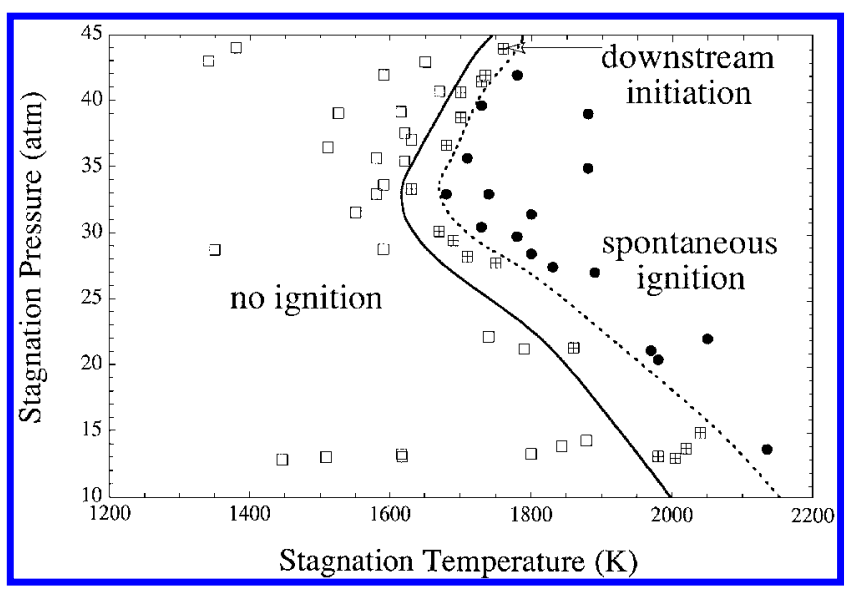

Fig. 6 Limit boundaries of spontaneous ignition and downstreaminitiated ignition in terms of the stagnation pressure and stagnation temperature; symbols are the experimental data. noted that the downstream mode of self-ignition was also reported in the experiments by Whitehurst et al. ${ }^{8}$ using clean air, in which the propagation speed was argued to be that of a detonation wave. Furthermore, although the unsteady nature of the downstream-initiated combustion was noticed in Ref. 8, the recorded images of the present investigation demonstrate that the second ignition mode becomes unsteady only when the stagnation pressure exceeds $25 \mathrm{~atm}$. Below 25-atm stagnation pressure, this downstream-initiated ignition mode is stable and well defined.

The nonmonotonic ignition response observed in the present investigation is expected to be general in nature, even though vitiated air was used. We shall demonstrate in the next section that most constituents of the vitiated air correlate well with the temperature in the heater. As such, the amount of contamination is approximately fixed when the stagnation temperature is held constant. Furthermore, because the Mach number and the injection strut height are kept constant in the present experimentation, the local residence time mainly depends on the stagnation temperature. Therefore, for a given stagnation temperature and, hence, a fixed mixture residence time, the influence of chemical kinetics can be isolated with pressure variations.

Figures 7 and 8 show the ignition response with pressure variations at two different stagnation temperatures and, hence, two different levels of chemical contamination and aerodynamic residence time. Specifically, Fig. 7 is for a stagnation temperature of $1750 \pm 50 \mathrm{~K}$, showing that with increasing pressure the system changes from nonignitable, to downstream-initiatedignition, to spontaneous ignition, and finally to downstream-initiated ignition again. For a lower stagnation temperature of $1700 \pm 50 \mathrm{~K}$, shown in Fig. 8, the corresponding ignition response transitions from no ignition, to downstream-initiatedignition, to spontaneous ignition, to downstream-initiated ignition, and eventually to no ignition. Thus,

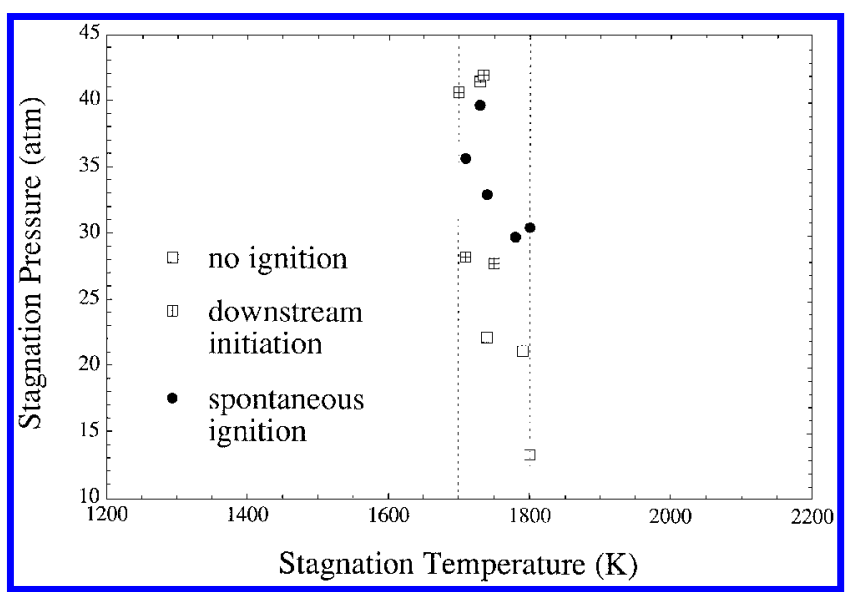

Fig. 7 Ignition response with pressure variations at the range of stagnation temperature around $1750 \pm 50 \mathrm{~K}$.

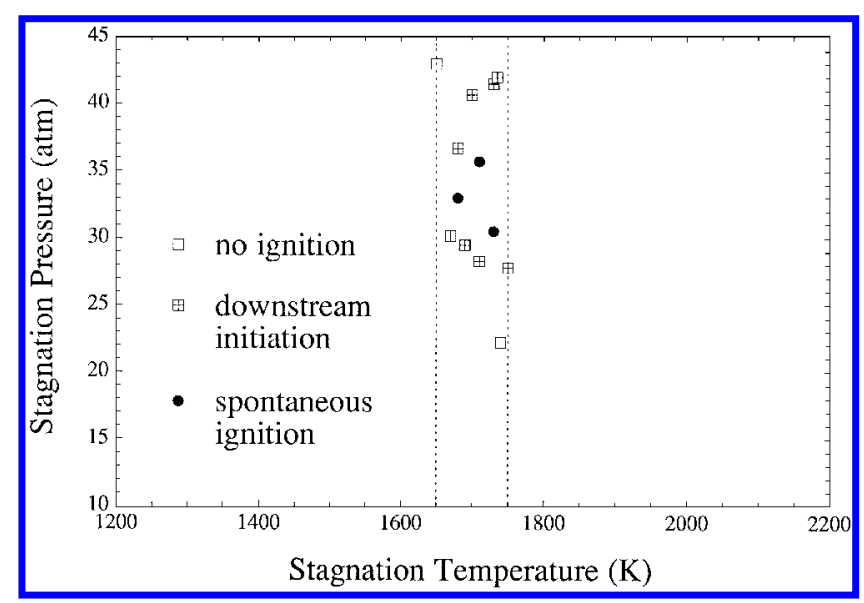

Fig. 8 Ignition response with pressure variations at the range of stagnation temperature around $1700 \pm 50 \mathrm{~K}$. 


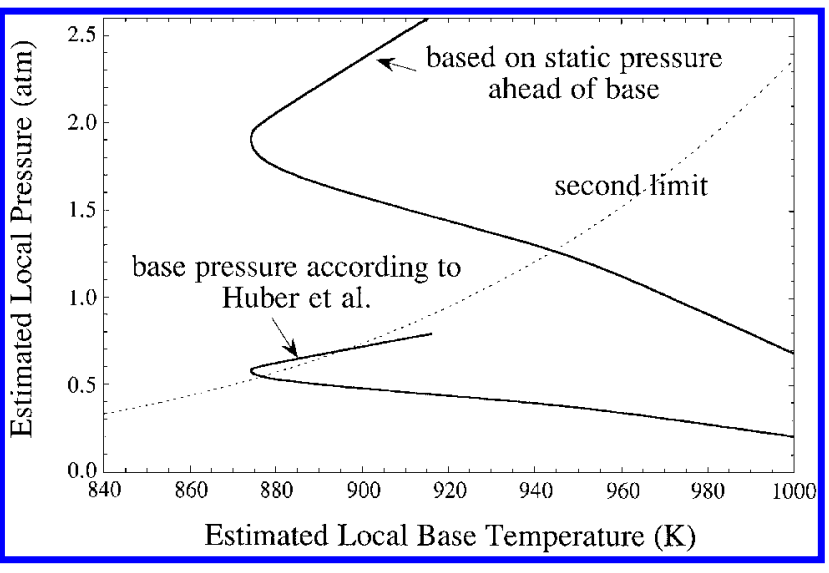

Fig. 9 Limit boundary of self-ignition in terms of the estimated local pressure and base temperature; dotted line represents the pressure dependence of the crossover temperature.

the nonmonotonic response of self-ignition with pressure variations is clearly demonstrated even with various degrees of air vitiation and different mixture residence times. The significant influence of chemical kinetics in the self-ignition of the supersonic hydrogen system is, therefore, clearly demonstrated.

\section{Self-Ignition Limits: Local Response}

Because self-ignition is possible only when the mixture's local residence time is comparable to the corresponding characteristic chemical time, it is of interest to express the experimental selfignition limit of Fig. 5 in terms of the local values of pressure and temperature. The local or recovery temperature in the base recirculation zone, $T_{r}$, can be estimated, following Ref. 4 , as

$$
T_{r}=F_{r}\left(T_{t}-T_{w}\right)+T_{w}
$$

where $F_{r}$ is the temperature recovery factor and $T_{w}$ the wall temperature. The value of $F_{r}$ is chosen to be 0.35 because it yields a $T_{r}$ similar to that of the coherent anti-Stokes Raman spectroscopy (CARS) measurement in a previous study ${ }^{7}$ using the present facility. It is noted that $F_{r}=0.4$ was used in the correlation of Ref. 4, for the strut base flow region. In a few experiments, two K-type thermocouples were imbedded in the strut base to monitor the base wall temperature variation. The measured wall temperature ranges between 450 and $500 \mathrm{~K}$, at various conditions. Thus, $T_{w}$ is assigned to be a constant of $475 \mathrm{~K}$ for simplicity.

However, the local pressure within the base recirculation zone is more difficult to assess due to the lack of accurate means of measurement. Two methods of estimation were attempted. The first is to simply utilize the freestream static pressure ahead of the strut base, using the relation in terms of the Mach number for a perfect gas with the ratio of specific heats being 1.36. This estimated freestream static pressure ahead of the strut base is actually similar to the pressure reading of the transducer closest to the fuel injector. Alternatively, the base pressure can be approximated using a base pressure coefficient at Mach 2.5 given in Fig. 11 of Ref. 4. Figure 9, therefore, summarizes the ignition limit in terms of the estimated local parameters. The corresponding local response of the self-ignition is still shown to exhibit a nonmonotonic behavior. In addition, the classical second explosion limit is plotted as a reference. It is seen that the positive slope of the ignition response at higher pressures resembles the variation of the crossover temperature. We, nevertheless, caution that the close agreement of the local response with the second ignition limit, when the assessment of the base pressure is based on Ref. 4, could be fortuitous.

\section{Computed Results on Effects of Air Vitiation on Ignition \\ Composition of Vitiated Air}

In the present experimentation the vitiated air of a given temperature was produced by a heater burning hydrogen-air along with oxygen replenishment so that the oxygen volume fraction within the resulting vitiated air is the same as that of normal air $(21 \%)$. The experimental design is based on the following one-step, irreversible reaction:

$$
\begin{gathered}
\alpha \mathrm{H}_{2}+\frac{1}{2}\left(\mathrm{O}_{2}+3.762 \mathrm{~N}_{2}\right)+\alpha\left(\frac{1}{3.762}+\frac{1}{2}\right) \mathrm{O}_{2} \\
\rightarrow \alpha \mathrm{H}_{2} \mathrm{O}+\left(\frac{\alpha}{3.762}+\frac{1}{2}\right) \mathrm{O}_{2}+1.881 \mathrm{~N}_{2}
\end{gathered}
$$

with the heat of combustion being $57.8 \mathrm{kcal} / \mathrm{mole}$. Thus, the desired air temperature can be represented by a single parameter, $\alpha$. The following discussion is based on the corresponding adiabatic condition, recognizing, however, that there was $12-17 \%$ heat loss through the heater.

Figure 10 presents the resulting temperature and mole fractions of some important species as a function of $\alpha$, at a representative pressure of $15 \mathrm{~atm}$. In addition to the one-step, irreversible approximation, calculations based on thermal equilibrium (infinite residence time in the heater) and perfectly stirred reactor ${ }^{9}$ (finite residence time) are included. The residence time is basically proportional to $(p V / T) / Q$, where $p$ is the pressure, $T$ the temperature, $V$ the volume of heater, and $Q$ the mass flow rate. Because the nozzle throat

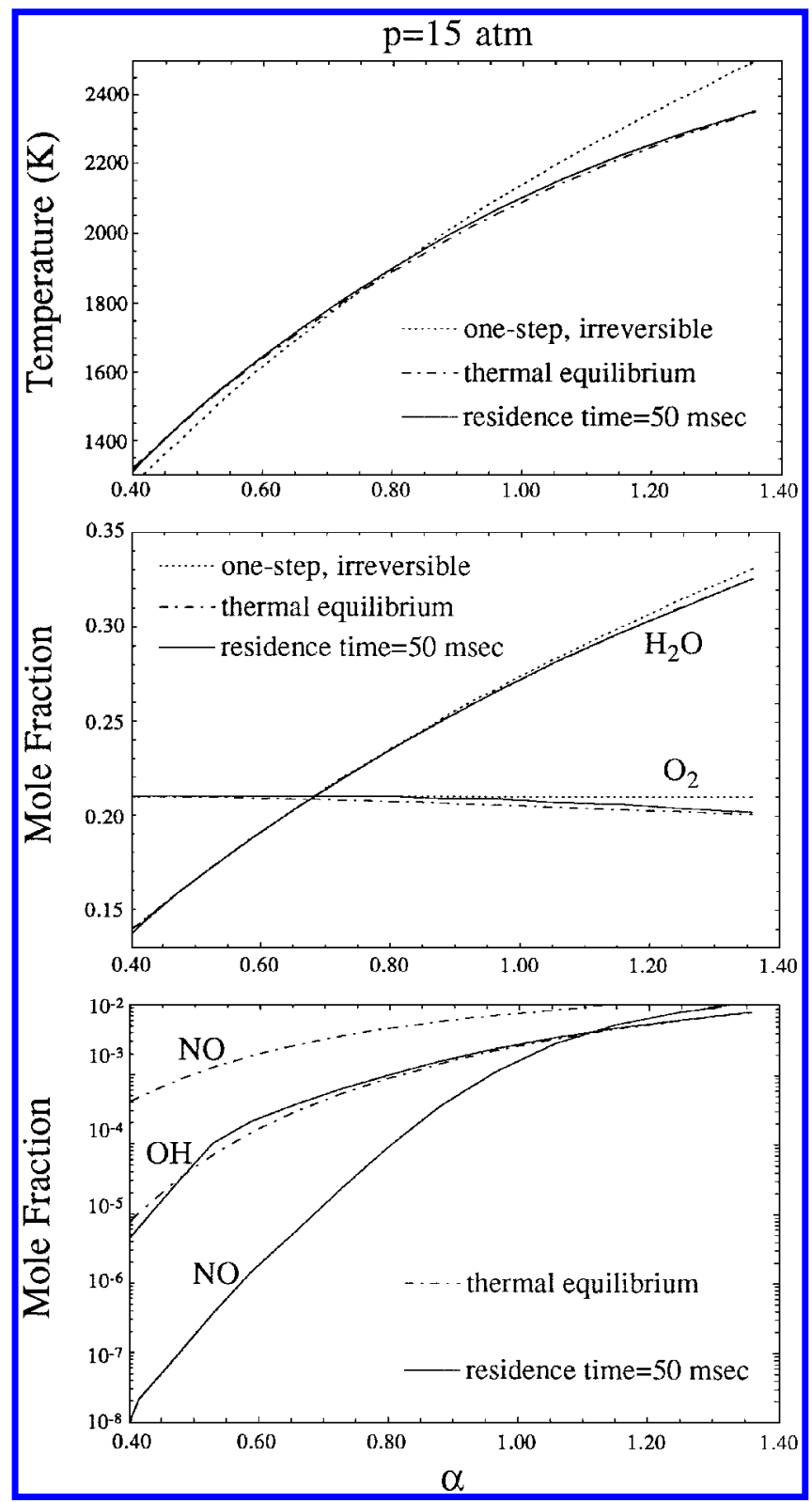

Fig. 10 Variations of temperature and mole fractions of $\mathrm{O}_{2}, \mathrm{H}_{2} \mathrm{O}$, NO, and $\mathrm{OH}$ with the vitiation parameter $\alpha$, at pressure of $15 \mathrm{~atm}$; calculations based on one-step irreversible reaction, thermal equilibrium, and residence time of $50 \mathrm{~ms}$ are compared. 
area is fixed, we have $Q \sim p / \sqrt{ } T$. As a result, the residence time is actually inversely proportional to $\sqrt{ } T$ alone. For the stagnation temperature of $2000 \mathrm{~K}$, the residence time is around $50 \mathrm{~ms}$, which represents a lower limit for the present study because $T_{t}$ is mostly smaller than $2000 \mathrm{~K}$, and there is an additional conical transition section between the heater and the nozzle. The reaction mechanism is taken from GRI-Mech $2.11,{ }^{\S}$ with the inclusion of rate constant correction and fall-off parameters for $\mathrm{H}_{2}+\mathrm{O}_{2}+\mathrm{N}_{2}=\mathrm{HO}_{2}+\mathrm{N}_{2}$ as suggested by Davidson et al. ${ }^{10}$

Figure 10 shows that the one-step reaction provides adequate estimations of temperature as well as the mole fractions of oxygen and water. It is seen that, whereas the important radicals such as $\mathrm{OH}$, $\mathrm{H}$, and $\mathrm{O}$ (only $\mathrm{OH}$ is shown in Fig. 10) are nearly in equilibrium, the amount of $\mathrm{NO}$ contamination is sensitive to the residence time due to the slowness of the associated reactions. It is also noted that, within the temperature range of investigation, more that $20 \%$ of water and 10-1000 ppm of $\mathrm{NO}$ are present in the resulting vitiated air. Furthermore, radicals such as $\mathrm{OH}, \mathrm{H}$, and $\mathrm{O}$ are relatively more pressure dependent.

Additional computations by considering effects of nozzle expansion have shown that most major species, including $\mathrm{H}_{2} \mathrm{O}$ and $\mathrm{NO}$, freeze rapidly (personal communicationfrom R. A. Yetter). Changes in the mole fractions of such transient species as $\mathrm{OH}, \mathrm{H}$, and $\mathrm{O}$ are noticeable and are about factors of 5-10 smaller after expansion to Mach 2.5. However, the sensitivity of the ignition temperature to variations in these transient species during the expansion is small because of the appreciable amounts present in the vitiated air. That is, the slow, high-energy barrier initiation steps are overcome by the finite radical concentrations, and hence the radical pool growth is governed by the chain-branching process. Therefore, only effects due to the two contamination species, $\mathrm{H}_{2} \mathrm{O}$ and $\mathrm{NO}$, are studied. $\mathrm{H}_{2} \mathrm{O}$ is considered because it is present in large quantities in the vitiated air, whereas NO is considered because of its nonlinear catalytic effect in assisting ignition, as compared with the linear effects of $\mathrm{OH}, \mathrm{H}$, and $\mathrm{O}$.

In the following we shall systematically examine the effects of contamination on ignition via the individual and combined influences of $\mathrm{H}_{2} \mathrm{O}$ and NO. The prototypical configuration employed herein is the counterflow nonpremixed system in which a fuel mixture impinges against a heated oxidizer flow with a given strain rate $\kappa$. Forced ignition, such as that in the counterflow, is more realistic than the homogeneous systems in assessing the vitiation effects in that, in addition to chemical kinetics, convective and diffusive transport of heat and mass to effect local mixing and heating are also considered. The governing equations, boundary conditions, and numerical scheme can be found in Ref. 11. For the nonpremixed counterflow ignition of a fuel jet of given concentration, stretch rate, and system pressure, ignition can be achieved by increasing the temperature of the oxidizer jet. The ignition state, characterized by the ignition temperature, can be assessed when the concentration of such crucial radicals as $\mathrm{H}$ starts to increase rapidly.

\section{Effects of $\mathrm{H}_{2} \mathrm{O}$}

Figure 11 shows the lower portion of the conventional steadystate $S$ curve by plotting the peak mole fraction of the hydrogen radical as a function of oxidizer temperature, at various degrees of water contamination. The fuel stream is a $60 \% \mathrm{H}_{2} / 40 \% \mathrm{~N}_{2}$ mixture, and the oxygen mole fraction is fixed at $21 \%$. The pressure and strain rate are $1 \mathrm{~atm}$ and $200 \mathrm{~s}^{-1}$, respectively. The turning point of each response curve defines the corresponding ignition temperature. Figure 11 clearly demonstrates the inhibition effects of water on ignition in that the ignition temperature increases with increasing amounts of water contamination. Such an inhibition effect is known to result from the effectiveness of $\mathrm{H}_{2} \mathrm{O}$ as a third body in recombination reactions. ${ }^{6}$ At $20 \% \mathrm{H}_{2} \mathrm{O}$ contamination, which is a typical amount of water present in the experiments, the required ignition temperature is more than $100 \mathrm{~K}$ higher than that of the dry air. Nevertheless, although $\mathrm{H}_{2} \mathrm{O}$ addition to the hydrogen system inhibits

\footnotetext{
${ }^{\S}$ Bowman, C. T., Hanson, R. K., Davidson, D. F., Gardiner, W. C., Jr., Lissianski, V., Smith, G. P., Golden, D. M., Frenklach, M., and Goldenberg, M., http://www.me.berkeley.edu/gri_mech/.
}

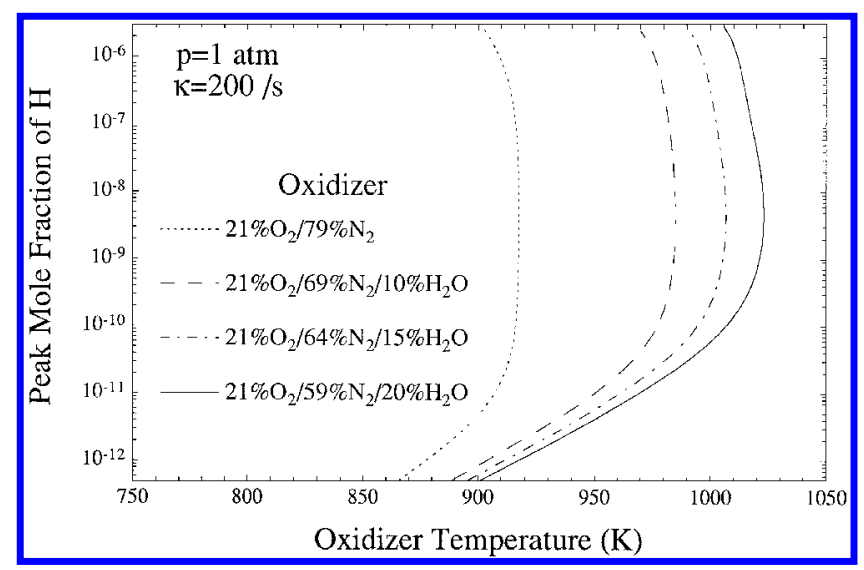

Fig. 11 Computed peak mole fraction of $\mathrm{H}$ as a function of oxidizer temperature for counterflowing $60 \%$ hydrogen in nitrogen vs heated oxidizer with various levels of water contamination, at pressure of 1 atm and strain rate of $200 \mathrm{~s}^{-1}$.

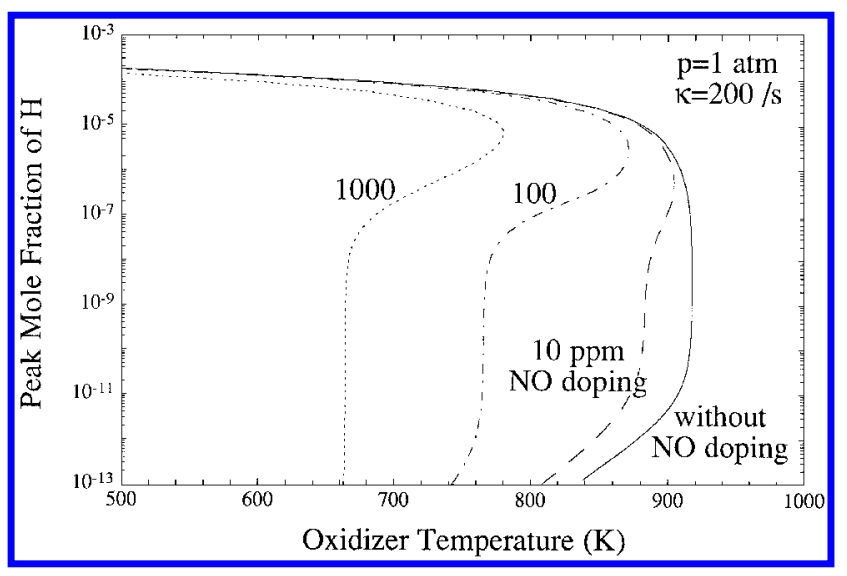

Fig. 12 Computed peak mole fraction of $\mathrm{H}$ as a function of oxidizer temperature for counterflowing $60 \%$ hydrogen in nitrogen vs heated air with various levels of $\mathrm{NO}$ doping, at pressure of $1 \mathrm{~atm}$ and strain rate of $200 \mathrm{~s}^{-1}$.

ignition, the overall shape of the nonmonotonic explosion limit has been shown to be preserved. ${ }^{6}$

\section{Effects of NO}

It is well established that, with a small amount of NO addition, the following reactions are the driving force behind the catalytic effect of $\mathrm{NO}$ in assisting ignition ${ }^{6}$ :

$$
\begin{gathered}
\mathrm{NO}+\mathrm{HO}_{2}=\mathrm{NO}_{2}+\mathrm{OH} \\
\mathrm{NO}_{2}+\mathrm{H}=\mathrm{NO}+\mathrm{OH}
\end{gathered}
$$

As a result, the net effect is to diminish the chain-terminatingeffect of reaction (2), $\mathrm{H}+\mathrm{O}_{2}+\mathrm{M}=\mathrm{HO}_{2}+\mathrm{M}$, by transforming it to be a chain-propagatingprocessinstead. Figure 12 shows the effect of NO doping in promoting ignition. It is seen that, with $1000 \mathrm{ppm}$ of NO doping, the ignition temperature can be reduced by as much as $150 \mathrm{~K}$ compared to that of the clean air. Furthermore, a recent study ${ }^{12}$ employing a counterflowing configuration demonstrates that, although the addition of NO alters the shape of the explosion limit, the resulting NO-affected ignition limit is basically only shifted toward lower temperatures and higher pressures.

\section{Combined Effects of $\mathrm{H}_{2} \mathrm{O}$ and $\mathrm{NO}$}

To demonstrate the competition of $\mathrm{H}_{2} \mathrm{O}$ inhibition and NO promotion in affecting ignition, Fig. 13 shows the effect of NO doping for the oxidizer with $20 \%$ water. Whereas significant reduction due to NO catalytic effect is seen in Fig. 13, it is unclear what the net contamination effects of $\mathrm{H}_{2} \mathrm{O}$ and $\mathrm{NO}$ are when compared with the dry, clean air cases. For instance, the ignition temperature is $\sim 917 \mathrm{~K}$ when clean air is the oxidizer. If the vitiated air contains $20 \% \mathrm{H}_{2} \mathrm{O}$ 


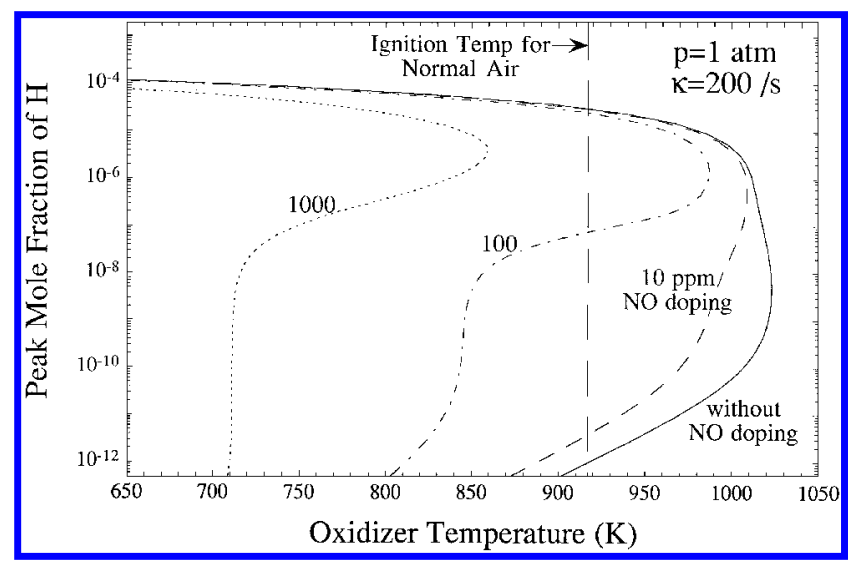

Fig. 13 Computed peak mole fraction of $\mathrm{H}$ as a function of oxidizer temperature for counterflowing $60 \%$ hydrogen in nitrogen vs heated oxidizer containing $20 \%$ water with various levels of NO doping, at pressure of $1 \mathrm{~atm}$ and strain rate of $200 \mathrm{~s}^{-1}$; ignition temperature when the regular, dry air is used as an oxidizer is indicated as a reference.

and 100-1000 ppm of NO, Fig. 13 indicates that the corresponding ignition temperature can be either higher than, equal to, or lower than $917 \mathrm{~K}$. Because within the range of the present experimental conditions the vitiated air is composed of $10-1000 \mathrm{ppm}$ of $\mathrm{NO}$ and more than $20 \% \mathrm{H}_{2} \mathrm{O}$, as shown in Fig. 10, the net effect of facility contamination is likely to be much smaller than the individual influences of $\mathrm{H}_{2} \mathrm{O}$ and $\mathrm{NO}$ due to their competing contributions in effecting ignition. Therefore, it is reasonable to suggest that the present experimental results are of direct relevance to practical situations in which the actual oxidizer source is dry, clean air.

\section{Concluding Remarks}

In the present study we have experimentally determined the limiting boundary of self-ignition by using a model scramjet combustor, in which the sonic gaseous hydrogen is injected parallel from the base of a blade-like strut into a supersonic vitiated airstream. The stagnation pressure and temperature studied ranged from 1.0 to $4.5 \mathrm{MPa}$ and from 1300 to $2200 \mathrm{~K}$, respectively. It is found that the self-ignitionlimit, in terms of either globalor local values of pressure and temperature, exhibits a nonmonotonic behavior resembling the first and second limits characterizing the homogeneous hydrogenoxygen explosions. Specifically, for a given temperature, increasing pressure from a low value can render a nonignitable mixture to become ignitable and then nonignitableagain. This correspondenceindicates the importance of the competition between chain-branching and chain-terminationreactions and demonstrates the inadequacy of the global reaction approximation as well as its inability to account for the complex chemical competition. Additional assessment of the contamination effects on the present experimental data is performed through simulation of counterflow ignition with detailed chemistry and transport properties. Computational results demonstrate, for the present experimentalconditions, that, because of the counterbalancing influence of the $\mathrm{H}_{2} \mathrm{O}$-inhibition and $\mathrm{NO}$-promotion reactions in effecting ignition, the combined contamination effects are expected to be much smaller than the individual contribution of these major contamination species.

\section{Acknowledgments}

The participation of Princeton University was supported by the U.S. Air Force Office of Scientific Research under the technical monitoring of J. M. Tishkoff, whereas that of the Chinese Academy of Sciences was supported by the Expert Committee of Aerospace Technology Area of the National 863 Program of the People's Republic of China through Contract 863-2-2-3-3. We appreciate fruitful discussions with R. A. Yetter of Princeton University.

\section{References}

${ }^{1}$ Cheng, S.-I., "Hypersonic Propulsion," Progress in Energy and Combustion Science, Vol. 15, No. 3, 1989, pp. 183-202.

$\checkmark 2$ Law, C. K., "Mechanisms of Flame Stabilization in Subsonic and Supersonic Flows," Major Research Topics in Combustion, edited by M. Y. Hussaini, A. Kumar, and R. G. Voigt, Springer-Verlag, New York, 1992, pp. 201-236.

${ }^{3}$ Tishkoff, J. M., Drummond, J. P., Edwards, T., and Nejad, A. S., "Future Direction of Supersonic Combustion Research: Air Force/NASA Workshop on Supersonic Combustion,” AIAA Paper 97-1017, Jan. 1997.

${ }^{4}$ Huber, P. W., Schexnayder, C. J., Jr., and McClinton, C. R., "Criteria for Self-Ignition of Supersonic Hydrogen-Air Mixtures," NASA TP-1457, Aug. 1979.

${ }^{5}$ Nishioka, M., and Law, C. K., "A Numerical Study of Ignition in the Supersonic Hydrogen/Air Laminar Mixing Layer," Combustion and Flame, Vol. 108, Nos. 1/2, 1997, pp. 199-219.

${ }^{6}$ Lewis, B., and von Elbe, G., Combustion, Flames, and Explosions of Gases, 3rd ed., Academic, New York, 1987, pp. 3-77.

${ }^{7}$ Li, J. G., Yu, G., Zhang, Y., Li, Y., and Qian, D. X., "Experimental Studies on Self-Ignition of Hydrogen/Air Supersonic Combustion," Journal of Propulsion and Power, Vol. 13, No. 4, 1997, pp. 538-542.

${ }^{8}$ Whitehurst, R. B., Krauss, R. H., and McDaniel, J. C., "Parametric and Time Resolved Studies of Autoignition and Flameholding in a Clean-Air Supersonic Combustor,” AIAA Paper 92-3424, July 1992.

${ }^{9}$ Glarborg, P., Kee, R. J., Grcar, J. F., and Miller, J. A., "PSR: A Fortran Program for Modeling Well-Stirred Reactors," Sandia National Labs., Sandia Rept. 86-8209, Livermore, CA, Feb. 1986.

${ }^{10}$ Davidson, D. F., Petersen, E. L., Röhrig, M., Hanson, R. K., and Bowman, C. T., "Measurement of the Rate Coefficient of $\mathrm{H}+\mathrm{O}_{2}+\mathrm{M} \rightarrow$ $\mathrm{HO}_{2}+\mathrm{M}$ for $\mathrm{M}=\mathrm{Ar}$ and $\mathrm{N}_{2}$ at High Pressures," Proceedings of the TwentySixth Symposium (International) on Combustion, Combustion Inst., Pittsburgh, PA, 1996, pp. 481-488.

${ }^{11}$ Nishioka, M., Law, C. K., and Takeno, T., "A Flame-Controlling Continuation Method for Generating S-Curve Responses with Detailed Chemistry," Combustion and Flame, Vol. 104, No. 3, 1996, pp. 328-342.

${ }^{12}$ Tan, Y., Fotache, C. G., and Law, C. K., "Effects of NO on the Ignition of Hydrogen and Hydrocarbons by Heated Counterflowing Air," Dept. of Mechanical and Aerospace Engineering, MAE Rept. 3036, Princeton Univ., Princeton, NJ, 1998. 
This article has been cited by:

1. Stefan Brieschenk, Sean O’Byrne, Harald Kleine. 2013. Laser-induced plasma ignition studies in a model scramjet engine. Combustion and Flame 160:1, 145-148. [CrossRef]

2. Vigor Yang, Jian Li, Jeong Yeol Choi, Kuo-Cheng LinIgnition Transient in an Ethylene Fueled Scramjet Engine with Air Throttling Part II: Ignition and Flame Development . [Citation] [PDF] [PDF Plus]

3. Onur TuncerCombustion in a Ramjet Combustor with Cavity Flame Holder . [Citation] [PDF] [PDF Plus]

4. Ahmed Abdelhafez, Adam Kareem, Ashwani GuptaSwirl Effects on Mixing in Free Underexpanded SupersonicNozzle Airflow . [Citation] [PDF] [PDF Plus]

5. P. Gerlinger, K. Nold, M. Aigner. 2009. Influence of reaction mechanisms, grid spacing, and inflow conditions on the numerical simulation of lifted supersonic flames. International Journal for Numerical Methods in Fluids $\mathrm{n} /$ $\mathrm{a}-\mathrm{n} / \mathrm{a}$. [CrossRef]

6. Eunju Jeong, In-Seuck Jeung, Sean O'Byrne, A. F. P. Houwing. 2008. Investigation of Supersonic Combustion with Angled Injection in a Cavity-Based Combustor. Journal of Propulsion and Power 24:6, 1258-1268. [Citation] [PDF] [PDF Plus]

7. J. R. McGuire, R. R. Boyce, N. R. Mudford. 2008. Radical-Farm Ignition Processes in Two-Dimensional Supersonic Combustion. Journal of Propulsion and Power 24:6, 1248-1257. [Citation] [PDF] [PDF Plus]

8. Ahmed Abdelhafez, Ashwani GuptaSwirl Effects on Shock Structure in Free Under-Expanded Supersonic-Nozzle Airflow . [Citation] [PDF] [PDF Plus]

9. Ahmed Abdelhafez, Ashwani GuptaNumerical Investigation of Oblique Fuel Injection in a Supersonic Combustor . [Citation] [PDF] [PDF Plus]

10. s JeyakumarMixing and Combustion in Coaxial High Speed Jets . [Citation] [PDF] [PDF Plus]

11. Thomas Anderson, Robert Lucht, Terrence Meyer, Tarun Mathur, Keith Grinstead, James Gord, Mark Gruber, Campbell CarterMeasurements of NO and $\mathrm{OH}$ Concentrations in Vitiated Air Using Diode-Laser-Based Ultraviolet Absorption Sensors . [Citation] [PDF] [PDF Plus]

12. Alessandro Sacco, Sean O'Byrne, Andrew Neely, Russell Boyce, Neil MudfordComparison of Computation and Measurements in a Supersonic Cavity Combustor . [Citation] [PDF] [PDF Plus]

13. S Jeyakumar, P Balachandran, S. Indira. 2006. Experimental Investigations on Supersonic Stream Past Axisymmetric Cavities. Journal of Propulsion and Power 22:5, 1141-1144. [Citation] [PDF] [PDF Plus]

14. S Jeyakumar, P BalachandranExperimental Investigations on Supersonic Stream Past Axisymmetric Cavities . [Citation] [PDF] [PDF Plus]

15. B. HAN, C. J. SUNG* M. NISHIOKA. 2004. EFFECTS OF VITIATED AIR ON HYDROGEN IGNITION IN A HIGH-SPEED LAMINAR MIXING LAYER. Combustion Science and Tecbnology 176:3, 305-330. [CrossRef]

16. Goro Masuya, Kenichi Takita, Katsuyoshi Takahashi, Fumio Takatori, Hiroyuki Ohzeki. 2002. Effects of Airstream Mach Number on H/N Plasma Igniter. Journal of Propulsion and Power 18:3, 679-685. [Citation] [PDF] [PDF Plus]

17. B. Han, C. Sung, M. NishiokaEffects of vitiated air on hydrogen ignition in a supersonic laminar mixing layer . [Citation] [PDF] [PDF Plus]

18. G. Yu, J. G. Li, X. Y. Chang, L. H. Chen, C. J. Sung. 2001. Investigation of Kerosene Combustion Characteristics with Pilot Hydrogen in Model Supersonic Combustors. Journal of Propulsion and Power 17:6, 1263-1272. [Citation] [PDF] [PDF Plus]

19. Adela Ben-Yakar, Ronald K. Hanson. 2001. Cavity Flame-Holders for Ignition and Flame Stabilization in Scramjets: An Overview. Journal of Propulsion and Power 17:4, 869-877. [Citation] [PDF] [PDF Plus] 